\title{
The Development of Aluminum Alloy Piston for Two-Stroke Cycle Engine by Powder Forging
}

\author{
Chul-Woo Park1,\# \\ 1 HYUNDAL STEEL, 444 Song-Dong, Nam-Gu, Pohang, Kyungbuk, South Korea \\ \# Corresponding Author / E-mail: p016535@empas.com, TEL: +82-54-271-1919, FAX: +82-54-271-1742 \\ (Manuscript received: Sep, 19, 2012 / Revised: Nov, 22, 2012 / Accepted: Nov, 23, 2012)
}

\begin{abstract}
The purpose of this paper is to investigate the influences on mechanical properties of two-stroke cycle motor pistons manufactured by casting, conventional forging and powder forging, through the comparison of characteristics, merits and disadvantages of each forming technology. For each forming technology, the optimal process parameters were determined through the experiments for several conditions, and microstructure, hardness, tensile strength and elongation of pistons are compared and analyzed. In conventional forging process, material temperature was $460^{\circ} \mathrm{C}$ and the die temperature was $210^{\circ} \mathrm{C}$ for the Al 4032. The optimal condition was found as solution treatment under $520^{\circ} \mathrm{C}$ for 5 hours, quenching with $23{ }^{\circ} \mathrm{C}$ water, and aging under $190^{\circ} \mathrm{C}$ for 5 hours. In powder forging process, the proper composition of material was determined and optimal sintering conditions were examined. From the experiment, $1.5 \%$ of $\mathrm{Si}$ contents on the total weight, $580^{\circ} \mathrm{C}$ of sintering temperature, and 25 minutes of sintering time were determined as the optimal process condition. For the optimal condition, the pistons had $76.4 \sim 78.3$ [HRB] of hardness, and $500[\mathrm{MPa}]$ of tensile strength after T6 heat treatment
\end{abstract}

KEYWORDS: Powder forging, Piston, Two-stroke cycle, DEFORM/3D

\section{Introduction}

Two-stroke cycle motor pistons conventionally have been manufactured by casting and forging technologies. The most popular manufacturing technology is casting, and it is divided into gravity casting technology ${ }^{(1)}$ and squeeze casting technology. ${ }^{(2)}$ The piston formed by casting technology has fragile microstructure because of pores, bad dimension accuracy from the irregular shrinkage, and low strength and elongation. The forging technology ${ }^{(3)}$ can consolidate the microstructures of pistons and improve the dimension accuracy, hardness and strength.

Powder Forging is the new technology having merits of powder metallurgy and precision forging technologies. Material is forged precisely to improve mechanical properties and uniformity of alloy composition. In powder forging technology, manufacturing costs can be down because products are flash-less forged by closed die. Moreover, products having holes or components having the complicated shape can be manufactured with no or less material loss. ${ }^{(4 \sim 7)}$ In spite of the considerable amount of work on casting, conventional forging, and powder forging, we can not find the study about comparing the manufacturing technologies, and analyzing the mechanical properties for each technology.

The purpose of this paper is to investigate the influences on mechanical properties of two-stroke cycle motor pistons manufactured by casting, conventional forging and powder forging, through the comparison of characteristics, merits and disadvantages of each forming technology. For each forming technology, the optimal process parameters were determined through the experiments for several conditions, and microstructure, hardness, tensile strength and elongation of pistons are compared and analyzed. To verity the theoretical result, we have carried o experiments using model material and FE-simulations using DEFORM/3D.

\section{Casting and Conventional Forging Piston}

The mechanical properties required for pistons are high strength, hardness, elongation, abrasion resistance, heat resistance because they work in high speed under high pressure and temperature. As the material for such requirements, AC8A and $\mathrm{Al} 4032$ were determined for casting and conventional forging pistons respectively. Chemical composition limits of the materials are shown in Table 1.

Table 1 Chemical Composition Limits of Aluminum Alloys

\begin{tabular}{|c|c|c|c|c|c|c|c|c|c|c|}
\hline & \multicolumn{10}{|c|}{ Chemical Composition } \\
\cline { 2 - 11 } & $\mathrm{Si}$ & $\mathrm{Cu}$ & $\mathrm{Mn}$ & $\mathrm{Mg}$ & $\mathrm{Cr}$ & $\mathrm{Zn}$ & $\mathrm{Ni}$ & $\mathrm{Fe}$ & $\mathrm{Ti}$ & $\mathrm{Zi}$ \\
\hline \multirow{2}{*}{$\mathrm{AC} 8 \mathrm{~A}$} & 11 & 0.8 & & 0.8 & & & 0.8 & & & \\
& - & - & 0.03 & - & 0.03 & 0.03 & - & 0.4 & 0.2 & 0.03 \\
& 13 & 1.3 & & 1.3 & & & 1.5 & & & \\
$\mathrm{~A} 1$ & 11 & 0.3 & & 0.8 & & & 0.5 & & & \\
4032 & - & - & 0.03 & - & 0.1 & 0.25 & - & 1.0 & 0.03 & 0.25 \\
& 13.5 & 1.3 & & 1.3 & & & 1.3 & & & \\
\hline
\end{tabular}


Casting piston used in the experiment was manufactured by gravity casting technology. This has been commercialized in industries. After casting, the pistons were heat-treated; solution treated under $500^{\circ} \mathrm{C}$ for 4 hours, quenched in $70^{\circ} \mathrm{C}$ water, and aged for 4 hours.

The press used in conventional forging experiment was 630 [ton] mechanical press. Die temperature was $210^{\circ} \mathrm{C}$ and the material temperature was $460^{\circ} \mathrm{C}$. As lubricant the graphite was used. After forging, pistons were solution treated under $520^{\circ} \mathrm{C}$ for 5 hours, quenched in $23^{\circ} \mathrm{C}$ water, and aged under $190^{\circ} \mathrm{C}$ for 5 hours.

Before the forging process, the experiment for visco-plasticity was performed with laminated black and white plasticine to investigate the workability and internal material flow. As lubricant, talc powder was used to separate material from die easily. The experiment was performed at 3 ton model material forming press with uniform ram speed of $1 \mathrm{~mm} / \mathrm{s}$.

In Fig. 1 (a), the result of the experiment shows the vertical cross section of skirt and boss region. Fig. 1 (b) shows the horizontal cross sections from head to boss region. Material flows outward extremely from the center of piston head to form the boss and skirt. In Fig. 1 (a), vertical cross section of boss, material deformed into thin slice is observed which can cause defects of product. In this experiment, however, material was formed without defects.
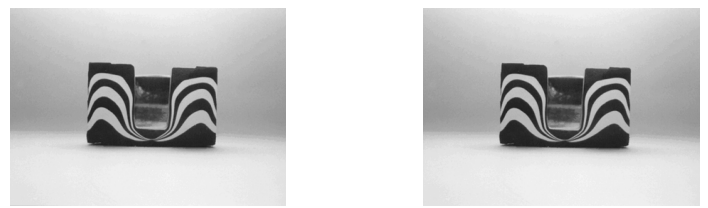

(a) Vertical Cross Section of Skirt and Boss Region
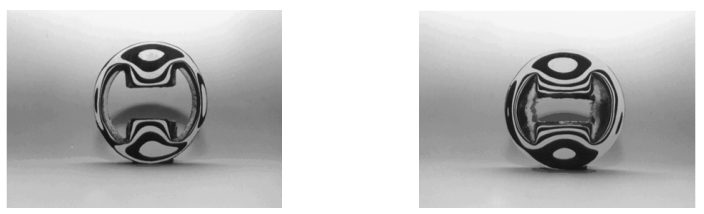

(b) Horizontal Cross Sections from Head to Skirt Region

Fig. 1 Material Flow Patterns of Plasticine Forged Pistons

\section{Powder Forging Piston}

\subsection{Mixing and Compacting}

The majority of powder used in experiments is Alumix-123(Al4.5 $\mathrm{Cu}-0.5 \mathrm{Mg}-0.7 \mathrm{Si}$ ) manufactured from ECKART, in Germany. The average size of powder is 200 mesh and theoretical density is 2.79 . The powder mixed by V-type mixer was compacted by 200 [ton] hydraulic press. The composition of material is shown in Table 2 . Generally compacting of $\mathrm{Al}$ alloy powder is performed within 2,000 4,000

Table 2 Chemical Composition Limits of Aluminum Alloys

\begin{tabular}{|c|c|c|c|c|c|c|c|}
\hline & $\mathrm{Al}$ & $\mathrm{Cu}$ & $\mathrm{Si}$ & $\mathrm{Ni}$ & $\mathrm{Mn}$ & $\mathrm{Mg}$ & Micro-wax \\
\hline Weight [\%] & 89.8 & 4.5 & 1.5 & 2.0 & 0.5 & 0.5 & 1.2 \\
\hline
\end{tabular}

[MPa]. In this experiment forming pressure is fixed as 2,000 [MPa]. The relative density of material measured by Archimedes method is 0.89 . Floating die was designed and used. This compacting die system can provide uniform distribution of material density after compacted.

\subsection{Sintering}

Table 3 Sintering Conditions

\begin{tabular}{|c|c|c|c|c|}
\hline Porcess & Dewaxing & Sintering & Cooling & Atmosphere \\
\hline $\begin{array}{c}\text { Temperature } \\
{\left[{ }^{\circ} \mathrm{C}\right]}\end{array}$ & 400 & 590 & 150 & $\mathrm{~N}_{2} \mathrm{Gas}$ \\
\hline $\begin{array}{c}\text { Holding Time } \\
{[\mathrm{min}]}\end{array}$ & $25 \sim 30$ & 25 & 30 & - \\
\hline
\end{tabular}

The sintering consists of 3 steps; dewaxing, heating, cooling. The purpose of dewaxing is removing wax contained in compact. This is required for perfect sintering. Usually sintering furnace used in mass production has continuous 3 zones with different temperature. Compacts are moved by conveyer belt system through these zones so sintering process can be performed continuously. In this paper, all these sintering process was performed at one-chambered furnace. And the relative density of sintered compact was measured 0.9 . Sintering conditions are shown in Table 3.

\subsection{Forging}

The temperatures of preform and die were $450^{\circ} \mathrm{C}$ and $250^{\circ} \mathrm{C}$ respectively. They were controlled automatically by heating control system. The graphite was used as lubricant. After forming, the products were heat-treated $\mathrm{T} 6$; solution treated under $510^{\circ} \mathrm{C}$ for 30 minutes and aged under $190^{\circ} \mathrm{C}$ for 18 hours. The formed pistons by each process are shown in Fig. 2.

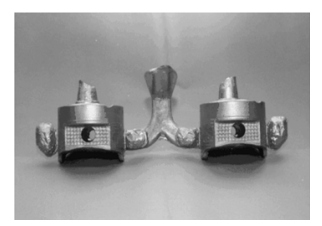

(a) Casting Piston

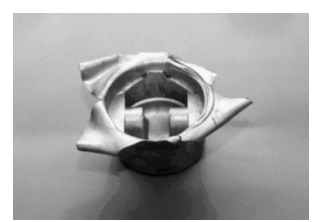

(b) Conventional Forging Piston

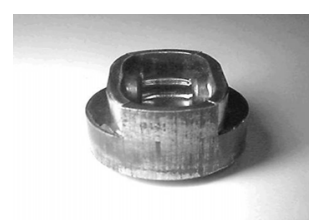

(c) Powder Forging Piston

Fig. 2 Pistons formed by each process 


\section{Preform design by FEM simulation}

The FEM simulation by DEFORM/3D, one of mostly used software in analysis of metal forming, was carried out. The relative density test[KS standard D 0033] and ring compression test were carried out in order to estimate the relative density and friction coefficient of the preform. The relative density of 0.92 and friction coefficient of 0.28 were obtained from ring compression test and used as the input parameter in FEM simulation. The flow stress of specimen at $450^{\circ} \mathrm{C}$ and dies $250^{\circ} \mathrm{C}$ was assumed as a function of strain-rate, and it was acquired from MTS(Material Test System) test. The equation is shown as follows. ${ }^{(7)}$ The top and bottom dies were consider as being rigid, while the workpiece as being powder. The axis of symmetry and the direction of movement prescribed to the top die are highlighted. A die velocity of $10 \mathrm{~mm} / \mathrm{s}$, obtained from industrial conditions, was applied to the top die.

$$
\bar{\sigma}=36.5 \times \bar{\varepsilon}^{0.55}[\mathrm{MPa}]
$$

\section{Result and Preform design by FEM simulation}

\subsection{Microstructure}

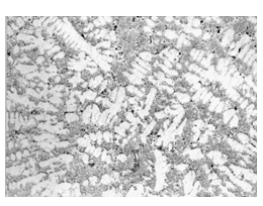

Head

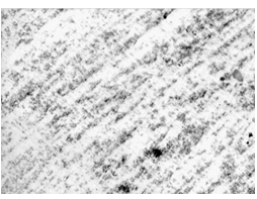

Head

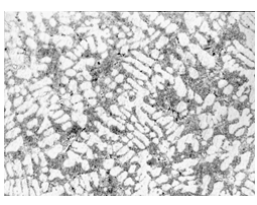

Boss

(a) Casting piston

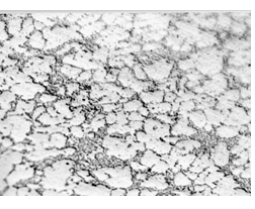

Boss

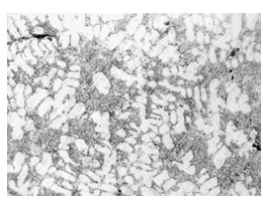

Skirt

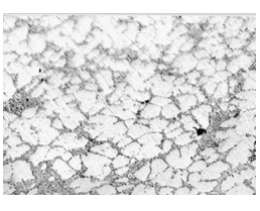

Skirt (b) Conventional forging piston

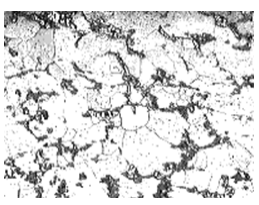

Head

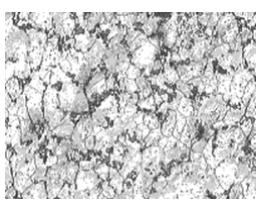

Boss

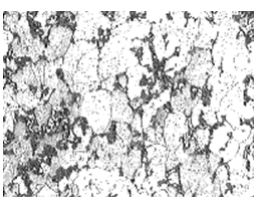

Skirt (c) Powder forging piston

Fig. 3 Microstructures of Casting, Conventional Forging and Power forging piston

Fig. 3 shows the microstructures of casting, conventional forging, and powder forging pistons in regions of head, boss, and skirt. Fig. 3 (a) shows dendrite structure in every region. During the solidification of pouring, dendrite of pure aluminum solidifies and eutectic of $\mathrm{Al}-\mathrm{Si}$ is filled into the space within the dendrite. Solidified pure aluminum and compound of $\mathrm{Si}$ are shown in white and gray color, respectively. In case of microstructure of conventional forging piston (Fig. 3(b)), structure is severely deformed by punch in head region, and uniform in boss and skirt region. Dense structures are observed in head, boss, and skirt regions of conventional forging piston. In Fig. 3 (c), pores existed in sintered preform are crashed and the structure become minute and dense. Eutectic around grain boundary and precipitation hardened structures are observed.

\subsection{Hardness}

Hardness of piston is an important factor that affects directly to impact resistance and abrasion resistance. Hardness of casting, conventional forging, and powder forging piston were measured. Fig. 4 shows hardness on head region of pistons. Hardness of powder forging piston is slightly higher than that of conventional forging piston. Casting piston is lower than other pistons. The hardness of piston can be increased by conventional forging or powder forging.
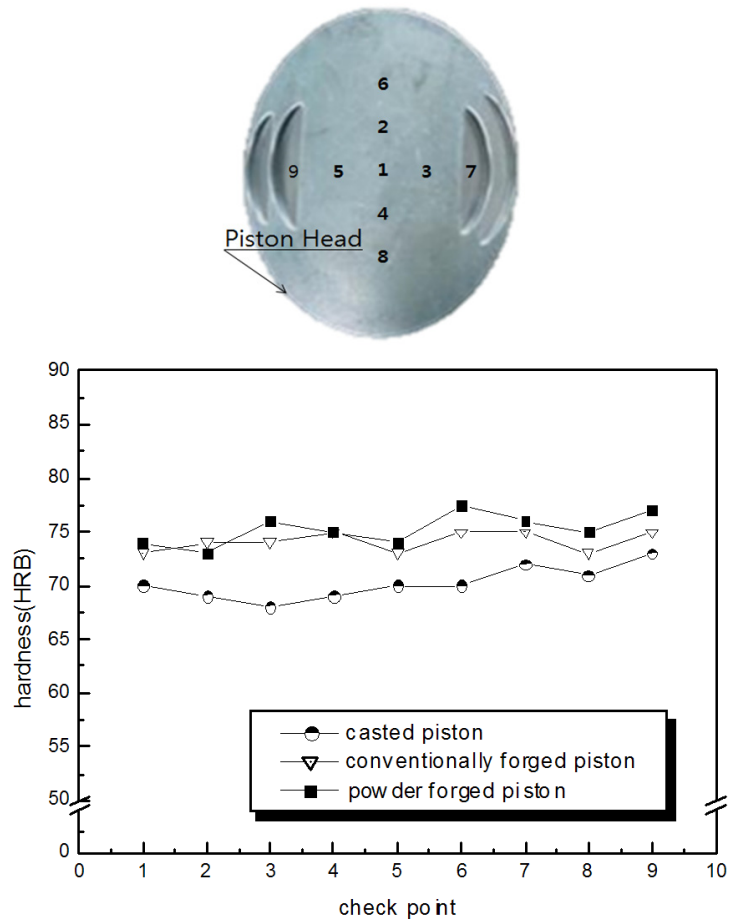

Fig. 4 Hardness on Head region of piston

\subsection{Tensile strength and elongation}

Specimens for tensile strength were provided and tested on mechanical MTS(Material Test System). Result of the experiment is shown in Table 4. For tensile strength, conventional forging piston is higher than casting piston and powder forging piston is higher than casting and conventional forging piston. For elongation, conventional forging piston was measured the highest. Powder forging piston is 3.3 times higher and conventional forging piston is 5.6 times higher than casting piston. 

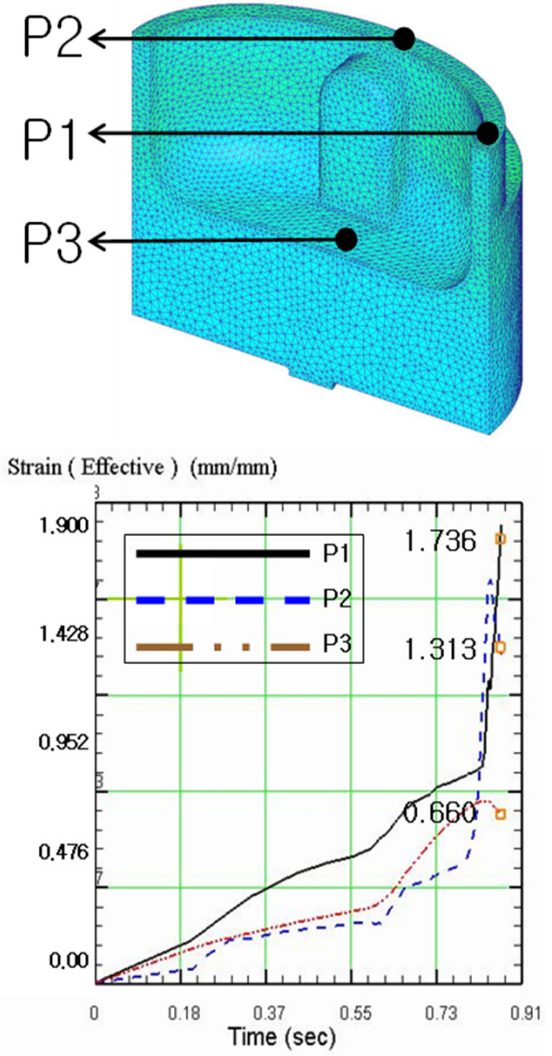

Fig. 5 Effective strain distribution of the forged bilet

Table 4 Comparison of pistons on mechanical properties at Head region

\begin{tabular}{|l|c|c|}
\hline \multicolumn{1}{|c|}{ Mechanical Properties } & $\begin{array}{c}\text { Tensile strength } \\
(\mathrm{MPa})\end{array}$ & $\begin{array}{c}\text { Elongation } \\
(\%)\end{array}$ \\
\hline Casting Piston & 232 & 2.4 \\
\hline Conventional Forging Piston & 299 & 13.4 \\
\hline Powder Forging Piston & 500 & 8.0 \\
\hline
\end{tabular}

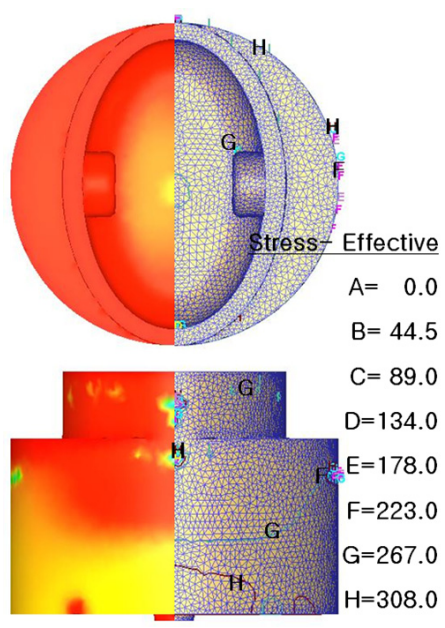

Fig. 6 Effective stress of powder forging

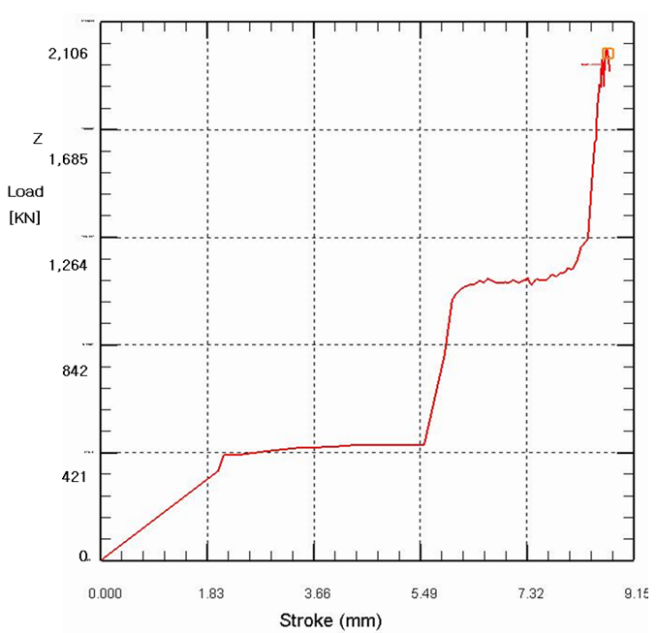

Fig. 7 Result of FEM simulation for the stroke

Fig. 5 gives the shape and strain distribution of the forged billet, each side of which can be clearly divided into three representative districts. As Shown in Fig. 5, the strain of point 1 and 2 are remarkably larger than at point 3 . And the strain curves at points 1 and 2 are similar.

Fig. 6 represents the stress-effective distribution of powder forging piston which is the uniform distribution in the aggregate. Fig. 7 show the variations of the computed total loads with the process stroke. It is observed that the computed total loads at steady-state are in good agreement. It can be seen that the maximum load in performing process is about $2,095[\mathrm{kN}]$.

\section{Conclusion}

In the present study, pistons were manufactured by conventional forging and powder forging technology. To investigate the influences on mechanical properties by each piston forming technologies, microstructure, harness, tensile strength and elongation of the pistons casted, conventionally forged, and powder forged were compared. By the experiment for visio-plasticity with laminated black and white plasticine, the workability and internal material flow during conventional forging were investigated. In the region of head, material deformed into thin slice was observed, and excessive deformation can cause defects of product.

(1) In the case of microstructure, the fine microstructure of the conventional forging piston was accomplished by destruction of dendrite. But in the powder forging piston, the fine grain boundary which was already existed by sintering was highly concentrated after forging process. In all parts of casted piston, the uniform microstructure is observed, but in the conventional forging piston, the microstructure is partially different.

(2) Powder forging can improve tensile strength about 2 times more than that of casting piston. For elongation, however, conventional 
forging is the most effective forming technology. The result indicates that conventional forging piston is superior for crack from shock to other pistons.

\section{REFERENCES}

1. Nikolay, A. B., Evgeniya, A. N., and Dmitry, G. E., 1999, "Casting Alloys of the Al-Ce-Ni System: Microstructural Approach to Alloy Design," Materials Science and Engineering, Vol. 271, Issues 1-2, pp. 134 142.

2. Yue, T. M., and Chadwick, G. A., 1996, "Squeeze Casting of Light Alloys and Their Composites," Journal of Materasls Processing Technology, Vol. 58, Issues 2-3, pp. 302 307.

3. Iwata, Y., Mae, S.,Urai, Y., and Tsunoda, T., 1989, Aluminium Alloy having an Excellent Forgibility, US Patent: 4889557.

4. Sutradhar, G., Bashashwan, A. A., Jha, A. K., and Kumar, S., 1997, "Closed die axisymmetric forging of Sintered aluminium preforms," Journal of Material Processing Technology, Vol. 68, No. 1, pp. 19 22.

5. Downey, C. L., and Kuhn, H. A., 1975, "Designing P/M Preforms for Forging Axisymmetric Part," The International Journal of Powder Metallurgy \& Powder Technology, Vol. 11, No. 4, pp. 225 261.
6. Kim, Y. H., Bae, W. B., Kim, H. S., and Byun, H. S., 1998, “An Experimental Study on the Manufacturing Technology of an Engine Piston," Journal of the Korean Society of Precision Engineering, Vol. 15, No. 11, pp. 83 92.

7. Park, J. O., Kim, J. J., and Kim, Y. H., 2001, "Development of an Automated Die Design System for Powder Forging," KSPE Conference, pp. 1029 1032.

8. Park, J. O., Kim, K. J., Kang, D. Y., Lee, Y. S., and Kang, D. Y., 2001, "An Experimental study on the Optimization of Power Forging Process Parameters for an Aluminum-alloy Piston," Journal of Material Processing Technology, Vol. 113, No. 15 pp. 486 492.

9. Ghaei, A., and Mobahhedy, M. R., 2007, "Die Design for the Radial Forging Process using 3D FEM," Journal of Material Processing Technology, Vol. 184, Issues 1-3, pp. 19 26.

10. Kwon, H. H., 2000, "Forging Die Design using Ceramic Insert," Journal of the Korean Society of Machine Tool Engineers, Vol. 9, No. 3, pp. 9 17.

11. Jang, J. M., Cha, B. H., Seo, J. S., Ko, S. H., Son, S. H., Lee, W. S., and Na, Y. S., 2011, "Optimization of Powder Injection Molding Process by In-mold Rheology," Proceeding of Journal of the Korean Society of Machine Tool Engineers, Vol. 11, No. 4, pp. 128 129. 